\title{
Pigeon Fancier's Lung in Children
}

\author{
S. CHANDRA and H. EVERLEY JONES \\ From the Royal Hospital, Wolverhampton
}

\begin{abstract}
Chandra, S., and Jones, H. E. (1972). Archives of Disease in Childhood, 47, 716. Pigeon fancier's lung in children. Pigeon fancier's lung occurred in 3 children whose fathers kept pigeons. The clinical features included progressive breathlessness, cough, cynanosis, sweating, and inspiratory râles. Chest $x$-rays showed diffuse fine mottling. The serum gave positive precipitin tests to pigeon serum or droppings in each case. 2 cases were treated with steroids, but the importance of breaking the contact with pigeons is stressed.
\end{abstract}

Since the description by Reed, Sosman, and Barbee in 1965 there have been several accounts of lung disease in pigeon fanciers. The majority of these have occurred in adults but we have been able to find records of 10 cases under the age of 16 , the youngest being 8 years old. Only one of these occurred in a girl, and 4 cases were 15 years old (Shannon et al., 1969; Stiehm, Reed, and Tooley, 1967; Dinda, Chatterjee, and Riding, 1969; Chaptal et al., 1970; Hargreave et al., 1966). Of these, 6 were American, 3 British, and 1 French.

The condition is due to inhalation hypersensitivity in those who keep birds and is similar to the better known farmer's lung caused by exposure to mouldy hay, byssinosis in cotton workers, and several others.

Recently we have encountered three examples of this disease in Midland children. The keeping of pigeons in this part of the country is a popular hobby and a recent survey of Wolverhampton Council house tenants disclosed that $\mathbf{4 0 0}$ residents were known to keep pigeons. As the Council owns $52 \%$ of the houses, the actual number of fanciers probably lies between 500 and 800 (F. N. Garratt, personal communication, 1971).

\section{Case Reports}

Case 1. A 10-year-old boy, admitted with 6 weeks' history of progressive shortness of breath leading to dyspnoea at rest, was also noted to breathe noisily at night and to have become grey in colour. There was some weight loss, poor appetite, and listlessness at school. $\mathrm{He}$ had been in good health before and there was no family history of allergy or chest disease. The father kept pigeons and the boy had recently taken an interest in them.

Received 13 March 1972.
On examination he was thin, slightly cyanosed, and apyrexial. Respiratory rate 30 per minute. Chest expansion poor, fine inspiratory râles at the bases.

Investigations. $\mathrm{Hb} 13 \cdot 1 \mathrm{~g} / 100 \mathrm{ml}$, WBCs $11,300 /$ $\mathrm{mm}^{3}$, with a normal differential count. Tuberculin test negative. $X$-ray of chest showed miliary mottling throughout both lung fields. Serum gave positive precipitin tests to pigeon and budgerigar. ${ }^{\star}$ Skin tests to pigeon, budgerigar, hens, and eggs were all negative (Bencard Allergy Products). For respiratory function tests see Table.

He was treated with prednisone $30 \mathrm{mg}$ daily for 8 days, which was tailed off during the next 10 days. Rapid clinical and functional improvement was observed and he was discharged well. Contact with pigeons was broken and he has had no further symptoms.

Case 2. A boy, aged 12, three weeks before admission developed a cold and rapidly became breathless, so that he was unable to swim or run. His condition worsened despite antibiotics and he also began to sweat excessively. He was one of five children, the other four being normal. The father kept pigeons and was healthy and the mother had no symptoms. Shortly before he was taken ill he had begun to help his father in the pigeon loft.

On admission to hospital he was wasted, pale, and sweating. Weight $26.8 \mathrm{~kg}$. He was afebrile with a pulse rate of 120 per minute and respiratory rate of 40 per minute. The lungs expanded poorly but no adventitiae were heard. No other abnormalities were found.

Investigations. $\mathrm{Hb} 13 \cdot 7 \mathrm{~g} / 100 \mathrm{ml}$, WBCs $6,500 / \mathrm{mm}^{3}$. Differential count was normal. Sputum, a mixture of Staph. aureus, Haemophilus influenzae, and monilia cultured. Tuberculin test negative. Serum precipitin tests to pigeon serum were positive; chicken serum, weakly positive; Aspergillus fumigatus, negative, and

^See Acknowledgements. 
Pigeon Fancier's Lung in Children

TABLE

Respiratory Function Tests, Case 1

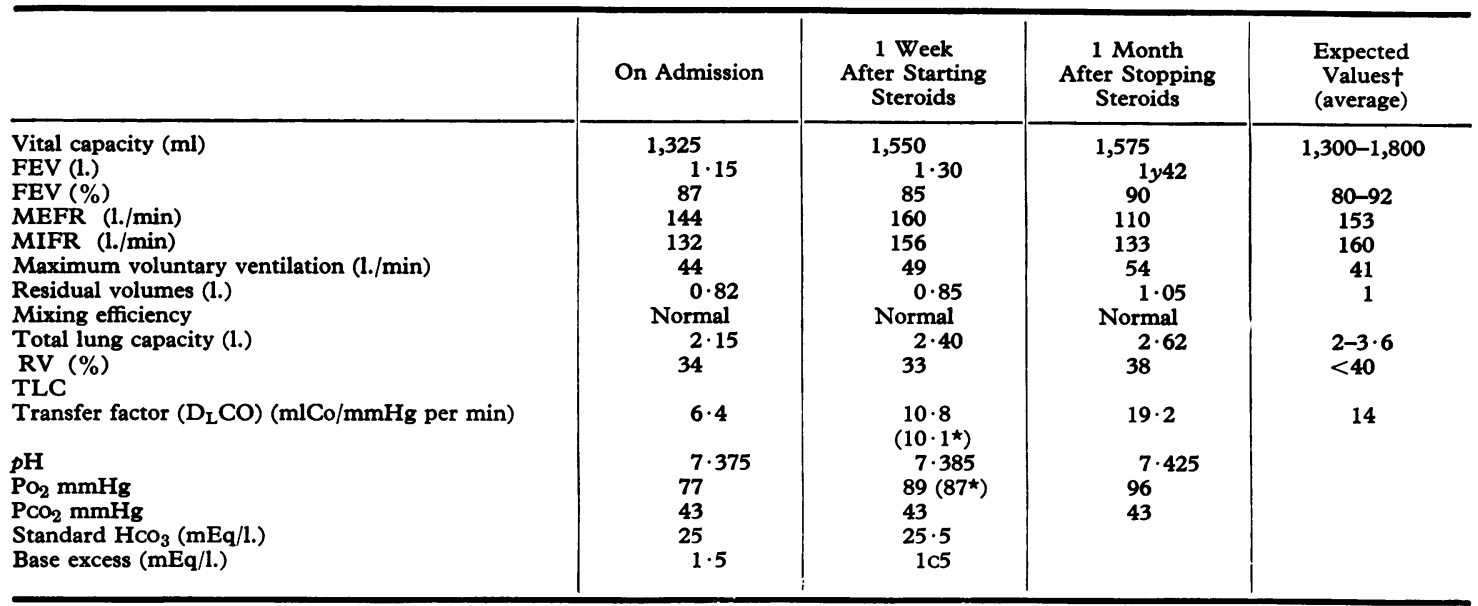

^After exercise.

†Giammona (1971), and Weng and Levison (1969).

budgerigar serum negative. $X$-ray of chest showed diffuse fine mottling.

Soon after admission his peak flow was only $125 \mathrm{ml}$ (expected, $300 \mathrm{ml}$ ). He was started on steroids and made very rapid improvement. In a week's time his peak flow had doubled to $240 \mathrm{ml}$, and radiologically the lung fields had virtually cleared. The steroids were stopped after two weeks.

The pigeons were disposed of and he has had no further contact with birds. 6 months later he remained well.

Case 3. A boy, aged 14, five weeks before admission developed a cough with a small amount of white sputum. He became progressively dyspnoeic and for one day had pain in the left shoulder. He had had no past illness of note and there was no family history of allergy or chest disease. The father kept pigeons.

On examination he was afebrile. Pulse 126 per minute. Respirations 40 per minute. He was cyanosed. His chest expansion was limited and there were fine inspiratory râles at both lung bases.

Investigations. $\mathrm{Hb} 12 \mathrm{~g} / 100 \mathrm{ml}$, WBCs $9,000 / \mathrm{mm}^{3}$. Differential count was normal. ESR $3 \mathrm{~mm} / 1$ hour. Sputum culture, Staph. aureus and pneumococci. Tuberculin test negative. Skin tests to pigeons and budgerigars negative. His serum gave positive precipitin reaction to pigeon serum and extracts of droppings from both pigeons and budgerigars. A repeat test 5 months later showed a reduction in intensity of reaction to both pigeon serum and droppings. ${ }^{\star} X$-ray of chest showed diffuse fine mottling (Fig.).

^See Acknowledgements.
In view of the bacteria isolated from the sputum, he was treated with erythromycin for a week but no other treatment was given. After a few days, considerable clearing of the shadows was noted on $x$-ray and he appeared completely recovered. The family ceased to keep pigeons and since then the boy has had no further symptoms.

\section{Comment}

The disease is similar to its adult prototype and

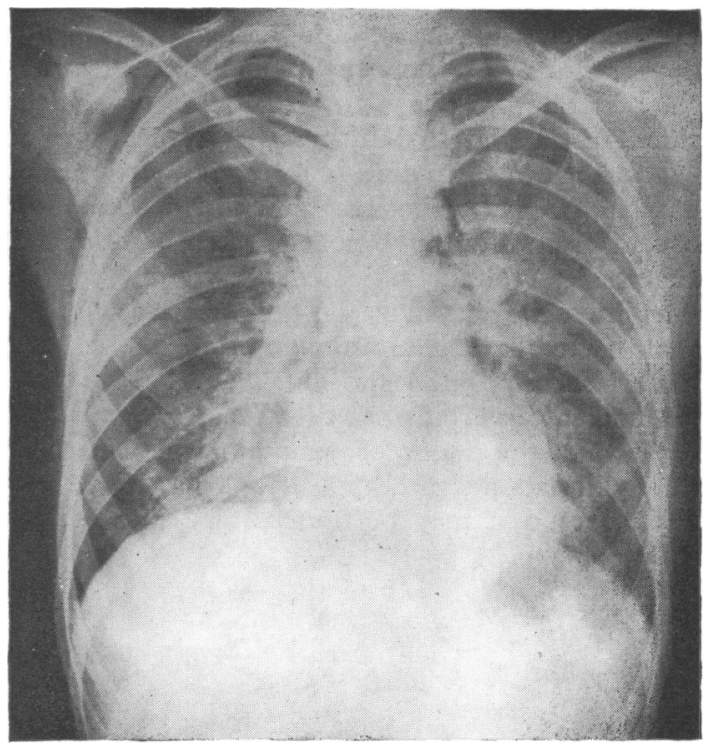

FIG.-Case 3, chest x-ray on admission, showing diffuse, fine mottling. 
the chief difference seems to be a more insidious onset of symptoms. The main physical signs are slight central cyanosis, tachypnoea at rest, and scattered fine inspiratory râles. Loss of weight is usual (Stiehm et al., 1967). $\quad X$-ray findings consist of sharp fine nodulation and reticulation or even honeycombing throughout the lung (Unger, Fink, and Unger, 1968). In the acute stage superimposed generalized, soft, patchy, and rather ill-defined densities tending to coalesce may be found and suggest secondary alveolar involvement (Unger et al., 1968). In the more chronic cases the changes are consistent with diffuse pulmonary fibrosis.

The disturbances in respiratory function tests are found in many other similar conditions producing hypersensitive pneumopathies, such as farmer's lung, maple bark stripper's disease, bagassosis, pituitary snuff taker's disease, mushroom-picker's disease, etc. The main features are reduction in vital airway capacity, little or no airway obstruction, reduction in diffusing capacity, arterial hypoxia, and small reduction in lung volume (Dinda et al., 1969; Schlueter, Fink and Sosman, 1969).

Histology of lung biopsy specimens has shown lymphocyte and plasma cell infiltration, thickened intra-alveolar septa, and several lipid-filled epithelial and giant cells (Stiehm et al., 1967).

The immunological response in this disorder appears to be a non-reaginic, probably delayed, type of hypersensitivity (Type IV), or arterial sensitivity reaction without histological change (Hargreave et al., 1966). Individuals with pigeon breeder's disease differ qualitatively and quantitatively in their response to certain pigeon antigen stimuli compared to healthy individuals. There is a tendency to binding of pigeon $\gamma$-globulin by the sera from the sensitive fanciers, as compared to sera from healthy breeders (Fink, Tebo, and Barboriak, 1969). Some fanciers with positive precipitin tests may have no pulmonary symptoms at all but tend to have rhinitis, the so-called 'pigeon fancier's nose' (Siegal and Ouellette, 1969).

A course of steroids has been recommended, and may reduce the period of symptoms particularly in acutely ill patients with hypoxaemia and breathlessness at rest but may be unnecessary since simple breaking of contact is often sufficient (Case 3). The protection of susceptible individuals has been suggested by wearing 'dust-masks', screening particles of more than $0.5 \mu$ diameter in size (Siegal and Ouellette, 1969).

Recognition of this condition is important since failure to do so may lead in time to permanent lung damage unless contact with pigeons is broken, as has been shown in adults (Schlueter et al., 1969; Godfrey, 1967), and as indicated by authors reporting cases in children (Chaptal et al., 1970; Stiehm et al., 1967).

We thank Professor Pepys, Institute of Diseases of the Chest, London, for the serum precipitin tests (materials and methods as described by Hargreave et al., 1966), and Dr. B. H. Bass for the lung function tests for Case 1. The late Dr. J. N. McCartney kindly supplied details of Case 3.

\section{REFERENCES}

Chaptal, J., Jean, R., Bonnet, H., Dumas, R., Serres, M., Robinet, S., and Ferrand, S. L. (1970). Miliaire pulmonaire chez l'enfant par 'maladie du poumon des éleveurs de pigeons'. Pédiatrie, $25,222$.

Dinda, P., Chatterjee, S. S., and Riding, W. D. (1969). Pulmonary function studies in bird breeder's lung. Thorax, 24, 374.

Fink, J. N., Tebo, T., and Barboriak, J. J. (1969). Differences in the immune responses of pigeon breeders to pigeon serum proteins. Fournal of Laboratory and Clinical Medicine, 74, 325.

Giammona, S. T. (1971). Evaluation of pulmonary function in children. Pediatric Clinics of North America, 18, 285.

Godfrey, S. (1967). Pigeon fancier's lung. Proceedings of the Royal Society of Medicine, 60, 1088.

Hargreave, F. E., Pepys, J., Longbottom, J. L., and Wraith, D. G. (1966). Bird breeder's (fancier's) lung. Lancet, 1, 445.

Reed, C. E., Sosman, A., and Barbee, R. A. (1965). Pigeonbreeders' lung. Fournal of the American Medical Association, 193, 261.

Schlueter, D. P., Fink, J. N., and Sosman, A. J. (1969). Pulmonary function in pigeon breeders' disease. Annals of Internal Medicine, 70, 457.

Shannon, D. C., Andrews, J. L., Recavarren, S., and Kazemi, H. (1969). Pigeon breeder's lung disease and interstitial fibrosis. American fournal of Diseases of Children, 117, 504.

Siegal, F. P., and Ouellette, J. J. (1969). Protecting pigeonhandlers. (Letter.) Lancet, 1, 733.

Stiehm, E. R., Reed, C. E., and Tooley, W. H. (1967). Pigeon breeder's lung in children. Pediatrics, 39, 904.

Unger, J. D., Fink, J. N., and Unger, G. F. (1968). Pigeon breeder's disease. Radiology, 90, 683.

Weng, T. R., and Levison, H. (1969). Standards of pulmonary function in children. American Review of Respiratory Diseases, 99, 879.

Correspondence to Dr. H. Everley Jones, The Royal Hospital, Wolverhampton, Staffordshire. 